\title{
PMO APPROACH IN CHOOSING THE OPTIMAL PROJECT GOVERNANCE FRAMEWORK FOR CONTRACTED ENGAGEMENT MODEL
}

\author{
Srđan Atanasijević ${ }^{1}$ \\ Tatjana Atanasijević ${ }^{2}$ (D) \\ Monika Zahar ${ }^{3}$
}

DOI: https://doi.org/10.31410/ITEMA.2019.171

\begin{abstract}
At Comtrade, Project Management Organization (PMO) is committed to providing the highest standard of project management services to guide projects from initial planning and design through engineering and construction and finally to execution and approvals.

One of the first steps of successful project governance is to develop and agree with customers the appropriate engagement model, which is typically determined by the client and by the type of its business environment that dictates the pricing model.

However, these agreements alone do not ensure satisfying results. PMO needs to be the driving force for establishing good and mature project governance management as a significant investment and crucial element for the success of every project and business growth.

This paper examines current pricing and engagement models, focusing on balancing its risk and benefits, discusses how a PMO shape project governance model to ensure project realization for a specific pricing model would. Research provides strategic approaches on how to identify and set a useful performance measurement metric and track key performance indicators aligned with diverse business models toward project goals accomplishments to build long-term success.
\end{abstract}

Keywords: Project Management, Project Management Office, Project Related KPI, Project Governance, Software Engineering Engagement Models, Performance Management Framework.

\section{INTRODUCTION}

$\mathrm{N}_{\mathrm{a} u}^{\mathrm{o}}$ owadays, complexity and rapid changing on markets make a concern for senior managers and necessitate developing a dynamic strategic framework to cope with those challenges. "Software is eating the world," wrote Marc Andreessen, co-founder and general partner of venture capital firm Andreessen Horowitz, in an essay published in The Wall Street Journal in 2011. In such economic pressure to reduce time to market for each company software is a crucial ingredient. Software engineering projects rarely operate in isolation within an organization and are usually delivered to satisfy broader strategic priorities [1]. This pressure has driven an increase in the number of projects undertaken simultaneously within organizations, and consequently, the complexity of managing their interdependencies [1]. Project Management Organization (PMO) is committed to provide the highest standard of project management services and to guide projects from initial planning and design through engineering, construction and finally to execution and approvals. Projects lacking adequate senior management support cannot deliver the expected business benefits to an organization.

\footnotetext{
$1 \quad$ Comtrade Group, Comtrade Digital Services, Dublin, Ireland

2 Comtrade Group, Comtrade Digital Services, Dublin, Ireland

3 Comtrade Group, Comtrade Digital Services, Dublin, Ireland
} 


\subsection{Organizational Governance and Project Governance}

Project governance and project success are in tight correlation. Governance systems cannot operate without the active support of the management system. In his article [2], Muller concluded that Governance starts at the corporate level and provides a framework to guide managers in their daily work of decision-making and action-taking. At the level of projects, Governance is often implemented through defined policies, processes, roles, and responsibilities, which set a framework for peoples' behavior and in turn influences the project.

Governance sets the boundaries for project management activities, by [2]:

- Defining the objectives of a project. These should be derived from the organization's strategy and clearly outline the specific contribution a project makes to the achievement of the strategic objectives,

- Providing the means to achieve those objectives. This is the provision of or enabling access to the resources required by the project manager,

- Controlling progress. Evaluate the appropriate use of resources, processes, tools, techniques, and quality standards in the project.

Without a governance structure, an organization runs the risk of conflicts and inconsistencies between the various means of achieving goals, such as processes and resources, thereby causing costly inefficiencies that negatively affect both smooth running and bottom-line profitability.

Project governance is the set of policies, regulations, functions, processes and responsibilities that define the establishment, management, and control of projects, programs, or portfolios [4].

Practical governance of project management ensures that the project portfolio of the organization remains aligned to organizational objectives, and is delivered efficiently and effectively, in a sustainable manner.

- Corporate Governance is the system of rules and practices that dictates how organizations are directed and controlled,

- Project Governance focuses more specifically on project activities.

This interrelationship is effectively presented in Figure 1.

The project governance framework needs to provide coherence between corporate governance and project governance, provide a guide for those involved in projects, and ensure that project roles and responsibilities are well understood. The management of a project is much like the governance of an organization [4]. Four key elements must be considered to support effective software project governance: portfolio management, project sponsor, PMO, and effective project management.

The role of management is to make decisions within the framework set by governance.

Governance of project management provides senior management confidence:

- An overview of all project management activities,

- A big picture of how organizations use resources,

- A risk assessment of their portfolio of projects,

- A rough metric of improvement in managing projects relative to others in the industry,

- Linkages of senior management with actual project execution management. 


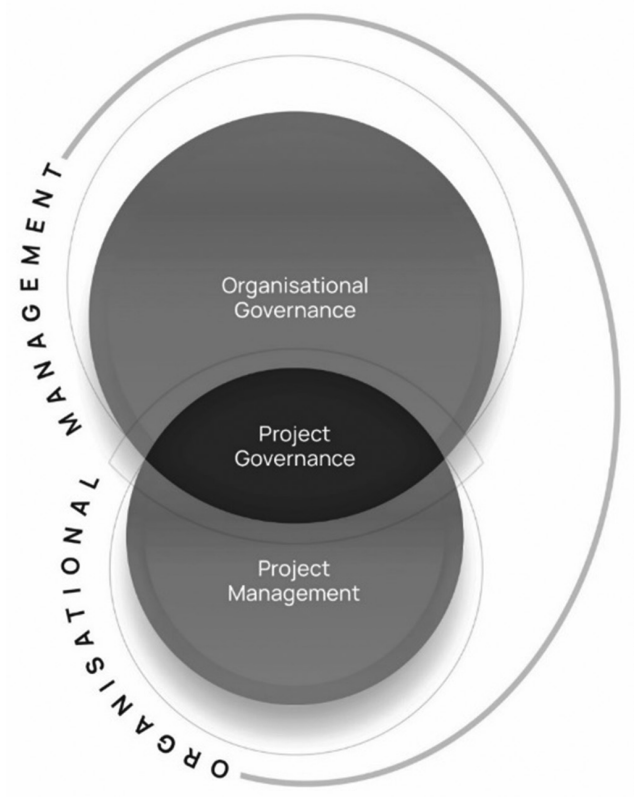

Figure 1. Project governance is the system of rules and practices that operates on a subset of a project and organizational metrics intended to align project goals with corporate targets
Approaches to governance vary by the particularities of organizations. Managers influencing the design of project governance should be aware of the importance of a stakeholder devotion to success [3]. The factor of project success comprises five sub-dimensions (project efficiency, organizational benefits, project impact, potential, and stakeholder satisfaction) $[2,3]$.

One of the first steps of successful project governance is to develop and agree with customers the appropriate engagement model, which is typically determined by the client and by the type of its business environment that dictates the pricing model.

In the separate chapter, we will discuss typical project engagement models in software engineering and KPI related to communicate project delivered value to the organizational and project stakeholders.

\section{METHODOLOGY}

In this article, we will use a case study type of research. Through the research process, we will apply a combined qualitative and quantitative research method.

By using qualitative methods, we will focus on recognizing the customer engagement models used today in practice by answering the question: what types of customer engagement models are present in the software development market today.

By applying quantitative analysis to a sample of project portfolios of the observed global midsized software companies, we will reduce the number of recognized engagement models to those that are more prevalent.

In the process of identifying representative engagement models, we will use the well-known principle formulated by Vilfredo Pareto, or the 80-20 rule, expressed in this case, that $80 \%$ of the contracted engagement models come from $20 \%$ of the dominant ones that we want to recognize.

Recognized dominant customer engagement models will be described in detail, and the second cycle of qualitative and quantitative analysis will be performed on them to identify key project metrics.

By quantitative analysis, we will identify a subset of project metrics that are of interest to corporate management.

To properly select and identify effective set of metrics for efficient project governance, we will focus on the following dimensions: monitoring the financial status of a project, its profitability, quality, customer satisfaction, resource utilization, and creation of new IP assets. 


\section{RESULTS}

Based on Harmon and others [6], the pricing decision is one of the most critical decisions that a firm can make, whether planning the introduction of a new information technology (IT) service or repositioning an existing IT service. They distinguish two groups of pricing modes based on the value it provides to the end customer: cost-based pricing models and value-based pricing models. Cost-based pricing models include the following strategies: Flat pricing, Tiered pricing, and Performance-based pricing [5]. Value-based pricing strategies were established on the premise of how customers perceive value [5]. Perceived value is defined in terms of the tradeoff between perceived benefits to be received and the perceived price for acquiring the product or service that delivers those benefits. These benefits are based on several drivers, including Economic-value drivers, Performance Value, Supplier Value, Buyer Motivation.

This approach is sometimes a little bit complicate to implement. In past years, this approach evaluates in a more straightforward and most effective. Today's market of software engineering services differentiates three remain pricing models (PRM) and based on them dozen customer engagement models (CEGM). Main pricing models are linear, non-linear, hand agile.

Linear pricing models are based purely on the relationship between time and material (effort and rate). The service provider is paid based on the resource provided or the effort spent on the required duration of the agreed time. We distinguish the following customer engagement models: dedicated team, time, and material (T\&M) and fixed price (FP).

Non-linear pricing models decouple the relationship between time and material. Typically, T\&M and FP do not offer much scope for modification and changes. Service providers have realized the necessity to be flexible to satisfy their customers. This demand has led to innovations in engagement models that suit varying needs. We distinguish the following engagement models: hybrid, managed service, outcome-based engagement and transactional.

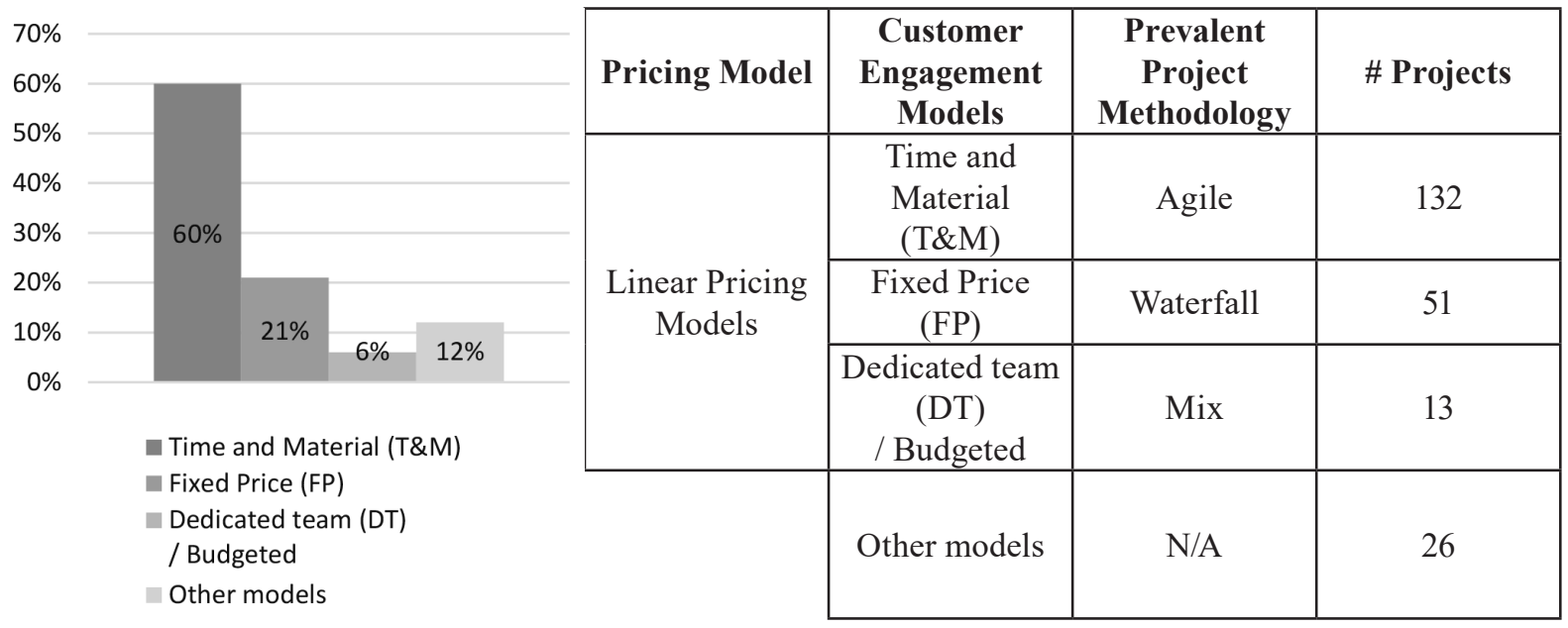

Figure 2. Typical Engagement models in middle software company used on $80 \%$ of projects, in 6 years

Finally, the third group of pricing models is based on an agile software delivery approach. Under Agile, we distinguish the following customer engagement models: capped T\&M, cost target contract, and incremental delivery CEGM. 


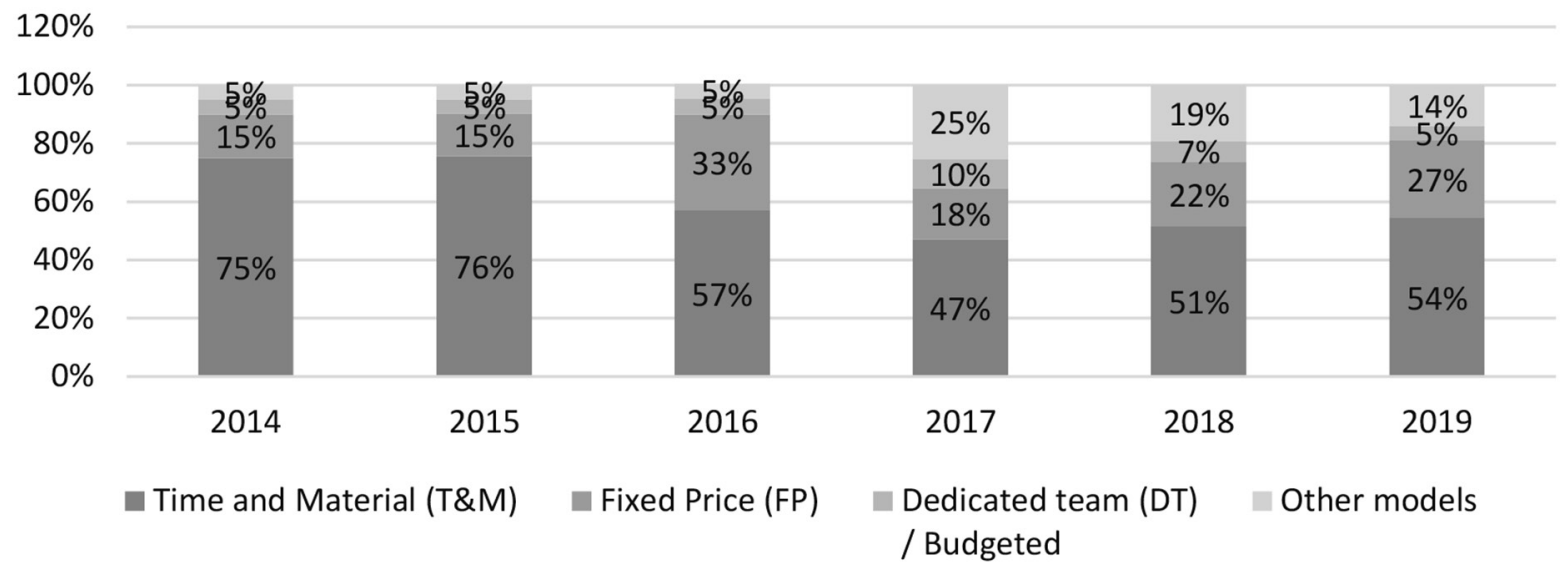

Figure 3. Typical breakdown of customer engagement models in middle size software company, in the six years

The survey was conducted on a data set covering the details of 220 projects for more than 100 customers in the six years (2014-2019). Research results identified that customers prefer just three customer engagement models. Figure 2 and Figure 3 presents key findings of this quantitative research: Time and material, Fixed price, and Dedicated team (budgeted) are recognized as prevalent customer engagement models, Table 1.

\section{DISCUSSION}

Customers should choose a pricing model based on the type of project they have. If they have a clear understanding of their project and a limited budget, then a fixed-price model should be used. Clients should avoid including lots of functionality in this case and instead focus only on core features. If the project is quite flexible and requirements change frequently, then the time $\&$ materials model should be applied.

Table 1. Main features of dominant customer engagement model in Software Engineering projects

\begin{tabular}{|c|c|c|c|c|}
\hline Model & When to use & Advantages & Disadvantages & Project type \\
\hline Fixed-price (FP) & $\begin{array}{c}\text { projects with limited } \\
\text { budgets and definite } \\
\text { deadlines. }\end{array}$ & $\begin{array}{l}\text { Finalized pricing. } \\
\text { Strict deadlines. } \\
\text { Predictability. } \\
\text { Little management. }\end{array}$ & $\begin{array}{l}\text { Rigid terms. } \\
\text { Long planning. } \\
\text { Miscommunication } \\
\text { risks. }\end{array}$ & $\begin{array}{l}\text { MVP } \\
\text { Limited features } \\
\text { Limited budget } \\
\text { Clear requirements }\end{array}$ \\
\hline $\begin{array}{c}\text { Time \& materials } \\
\text { (T\&M) }\end{array}$ & $\begin{array}{l}\text { projects with } \\
\text { changing } \\
\text { requirements and } \\
\text { long-term projects }\end{array}$ & $\begin{array}{l}\text { Flexible } \\
\text { requirements. } \\
\text { Hourly rates. } \\
\text { Product quality. } \\
\text { Transparency. }\end{array}$ & $\begin{array}{l}\text { Uncertain deadlines. } \\
\text { Undefined budget. } \\
\text { Need to manage the } \\
\text { process } \\
\text { Hard decisions. }\end{array}$ & $\begin{array}{l}\text { Unclear scope } \\
\text { Dynamic } \\
\text { requirements } \\
\text { Long term projects }\end{array}$ \\
\hline $\begin{array}{l}\text { Dedicated team } \\
\text { (DT) } \\
\text { / Budgeted }\end{array}$ & $\begin{array}{l}\text { business partners } \\
\text { with established } \\
\text { relationships }\end{array}$ & $\begin{array}{l}\text { Entirely predictable } \\
\text { budget, a monthly } \\
\text { payment based on } \\
\text { delivered hours. } \\
\text { The customer } \\
\text { manages it. }\end{array}$ & $\begin{array}{l}\text { Low efficiency for } \\
\text { short-term projects. } \\
\text { Team members have } \\
\text { fewer opportunities } \\
\text { to learn new } \\
\text { techniques }\end{array}$ & $\begin{array}{l}\text { Long partnership } \\
\text { Focus on } \\
\text { performance and } \\
\text { quality of services } \\
\text { Specialization }\end{array}$ \\
\hline
\end{tabular}

When parties have a long-term relationship, they can work according to the dedicated team or budgeted model. In a nutshell, customers must balance their expectations of quality, deadlines, and price. 
Table 2. Sample of KPI performance measures, recommended for specific customer engagement model

\begin{tabular}{|c|l|c|}
\hline Area & Project metrics & CEGM \\
\hline \multirow{5}{*}{ Finance } & Sales Revenue, Gross Profit, Gross Profit Margin (value and YoY) & All models \\
\cline { 2 - 3 } & Gross Profit per Delivered FTE, Billable Utilization & T\&M \\
\cline { 2 - 3 } & Total Costs, Cost of service delivery, Subcontractors cost & All models \\
\cline { 2 - 3 } & The ratio of estimated project costs to actual costs & Fixed Price \\
\hline \multirow{5}{*}{ Customer } & Customer Engagement & All models \\
\cline { 2 - 3 } & Customer Profitability Score & All models \\
\cline { 2 - 3 } & Customer Satisfaction Index, Customer Complaints & T\&M \\
\cline { 2 - 3 } & Service Level Agreement (SLA) failures & All models \\
\hline \multirow{5}{*}{ Quality } & Delivery capacity and YoY, effort (FTE), Subcontractors share & All models \\
\cline { 2 - 3 } & Utilization, Onsite Delivery effort & T\&M \\
\cline { 2 - 3 } & Done/Closed, Done/Lost resource requests, Monthly Lost Rev & T\&M \\
\cline { 2 - 3 } & Project Schedule Variance, Number of Change Requests & Fixed Price \\
\hline & Issues found by Customers and QA & All models \\
\cline { 2 - 3 } & Issues found in code review & All models \\
\cline { 2 - 3 } & Safety incidents & All models \\
\cline { 2 - 3 } & Milestones accuracy & Fixed Price \\
\hline
\end{tabular}

Once dominant customer engagement models have been identified, project metrics analysis is approached. Organizations need a reliable project performance measurement program to improve their software development process continuously [7,8]. Business process performance measurement and software process performance measurement tackle similar research questions: the development of methodologies and metrics to measure, control, manage, and improve a process. Business process performance measurement defines requirements for Key Performance Indicators (KPIs) that are ignored by the software metrics community. Based on the research of Guillermo Montero and other associates [9], they identified a set of 26 proposed key process indicators; a dashboard of 26 indicators narrowed from the original 83 has been created after using three consultation rounds seeking consensus within a panel of seven experts shown in Table 2. Based on that research and conclusions presented in the paper [9] they formulate criteria based on the following aspects, related to KPI:

- Contents should consider project indicators, economic/financial ratios, earned value analysis and indicators related to project risks;

- Data must be as specific and accessible as possible;

- Data collection needs to be efficient and cost-effective;

- Stakeholder's perspective has to be considered;

- The scorecard should be transferable.

Table 2 shows project metrics related to reporting by organizational areas and project sponsors. The CEGM column shows which metrics is applicable in which engagement model.

\section{CONCLUSION}

This paper examines current pricing and engagement models, focusing on balancing its risk and benefits, discusses how a PMO shape project governance model to ensure project realization for a specific pricing model would [10]. In this paper, we explore a subset of project metrics that are candidates for project governance. Project management should be monitored from the perspec- 
tive of project sponsors, company management, and customers [11]. The resulting KPIs should reflect the financial status of the project, the quality of deliverables, risks, customer and team satisfaction. Organizational management is interested in monitoring the realization of revenue and expenditure planning, profitability, resource utilization, current customer satisfaction [12]. Research provides strategic approaches on how to identify and set a useful performance measurement metric and track key performance indicators aligned with diverse business models toward project goals accomplishments to build long-term success.

\section{REFERENCES}

[1] Too, E. G., \& Weaver, P. (2014). The management of project management: A conceptual framework for project governance. International Journal of Project Management, 32(8), 1382-1394.

[2] Muller, R. (2017). Project governance. Routledge.

[3] Joslin, R., \& Müller, R. (2016). The relationship between project governance and project success. International Journal of Project Management, 34(4), 613-626.

[4] Alie, S. S. (2015). Project governance: \#1 critical success factor. In PMI® Global Congress 2015. Orlando, Florida: Project Management Institute.

[5] Association for Project Management. (2012). APM body of knowledge. (6th ed.). Buckinghamshire: Association for Project Management.

[6] Harmon, R., Demirkan, H., Hefley, B., \& Auseklis, N. (2009). Pricing Strategies for Information Technology Services: A Value-Based Approach. In 2009 42nd Hawaii International Conference on System Sciences (pp. 1-10). Big Island, HI, USA: IEEE.

[7] Atanasijevic, S. (2016). Approach to project management in dynamic reality - Differences between traditional and agile approaches. doi:10.13140/RG.2.2.10519.27047/1.

[8] List, B., Bruckner, R. M., \& Kapaun, J. (2005). Holistic software process performance measurement from the stakeholders' perspective. In 16th International Workshop on Database and Expert Systems Applications (DEXA'05) (pp. 941-947). Copenhagen, Denmark: IEEE.

[9] Montero, G., Onieva, L., \& Palacin, R. (2015). Selection and Implementation of a Set of Key Performance Indicators for Project Management. International Journal of Applied Engineering Research, 10(18), 39473-39484.

[10] Atanasijević, S. (2013). Case Study: How to establish global PMO Office. doi: 10.13140 / RG.2.2.18446.82247/1.

[11] Dragićević, D., Milosavljević, A., \& Atanasijević, S. (2013). Combination of traditional and agile project management methodologies on software project of health information system in Ministry of Defence of Republic of Serbia. In 16. International Conference of Quality Management. Belgrade: ICDQM.

[12] Atanasijević, S. (2019). Project Management on AI Projects. doi: 10.13140/ RG.2.2.10771.02080/1. 